\title{
Interactive comment on "Hydrological response in the Danube lower basin to some internal and external climate forcing factors" by I. Mares et al.
}

\section{Mares et al.}

ileana.mares@yahoo.com

Received and published: 22 September 2016

Dear Reviewer,

Thank you very much for your great support for the improvement our manuscript. We have taken into account your comments and suggestions and we hope you find our manuscript improved in comparison with the initial version. We also restructured a part of paragraphs, for a better understanding.

Many thanks for your help.

With best regards, Authors

In the following, I will give details about the changes done in manuscript, thanks to your comments/suggestions. 
"Studying the impacts of climate system on hydrology is the focus of many studies. Different from other studies that mainly focus on the internal climate factors, this study focuses on both internal and external climate forcing factors. This would give us a bigger picture of the hydrological impacts from the climate system. The manuscript also provides enough results to support their conclusions. With that being said, the manuscript is worth publishing. However, the manuscript is so poorly written that it is full of grammar errors. This will cause a lot of troubles for readers to understand. Therefore, I urge the authors use more efforts in writing. I highly suggest the authors do a line by line editing and perhaps seek help from colleagues or professional editing"

R.

Thank you very much for your positive appreciations related to contribution to scientific progress give by our paper. Sorry, mainly for the grammar errors. We have improved English.

" Correlation is heavily used in this study. However, can you give the physical explanation behind the high or low correlations? This can be done by providing some background knowledge on the feedbacks among these processes in the Introduction, or by providing more meaningful justification in the result section. "

$\mathrm{R}$. We have inserted more discussion and new references, both in the Introduction and in the result section.

"A good abstract usually begins with a general statement about the field of research which provides readers with a setting for the problem(s) to be addressed in the paper. I suggest the authors add this kind of information to the abstract."

R.

Printer-friendly version

This information was introduced in abstract.

"The authors give very brief information about other similar studies at the end of SecDiscussion paper tions 4.1 and 4.2. However, it would be better if this can be expanded a bit. For 
example, how do the results from this study compare to other previous studies? "

R.

We have tried to discuss our results in comparison with previous studies.

"Line 19: what does "simultaneously" mean here? Line 28: should "simultaneously"? Lines 48-49: "As shown in Cubasch et al. (1997) and Benestad and Schmidt (2009), it is difficult to distinguish . . ." reads better? Line 55: Should be "Brugnara et al. (2013) reviewed . ..." There are many more similar errors throughout the manuscript. Please modify them."

R. These modifications were achieved.

"Lines 61-67: Do you include greenhouse gases in this study? If not, you may not need to mention it here. But this will be up to the authors."

R.

These descriptions, concerning greenhouse gases were extracted.

"Line 83: "NAOl" is used before definition, even though it is defined in abstract. Line 95: Should be "for the first time"?"

R.

The modifications were achieved.

"Lines 117-125: It seems to me that the detail information about methodology needs to be moved to Section 3."

R.

We have moved these information on methodology in the Section 3.

Printer-friendly version

"Line 134: I could not find the section 4.3.2."

Discussion paper

R. 
Sorry for this mistake. The content of the section 4.3.2 was included, but we have forgotten to insert its title. Now everything is OK with this section. Thank you very much.

"Line 169: "girded" should be "gridded"?

R. OK.

"Line 240: serial correlation is not a common concept in hydrology, can you please provide the equation(s)."

R. We introduced the serial correlation coefficient formula (eq.2)

"Line 304: Is it a good idea to cite so many conference abstracts? The information provided by an abstract is very limited."

$R$. We have excluded some of the references which means conference abstracts, but not all, because some of them we consider to give important information, for instance, when we have presented for the first time the atmospheric index, GBOI, or when the Conference presentation was under PICO form, and in this case entire presentation is found online.

"Line 340: add the threshold 0.254 into Figure 6. Figure 6: Add notes to give the full names of the "nine predictors"."

R.

We have inserted the line representing the threshold $0.254(\mathrm{CL}=99 \%)$ in Figure 6, from the first version of the manuscript. Now, after we restructured the manuscript, the Figure 6 became Figure 5 in the new version. Also, we inserted this threshold in the next figure (now,Figure 6) thanks to your very good suggestion. We have given the full names of the "nine predictors".

Printer-friendly version

Please also note the supplement to this comment:

Discussion paper 
http://www.hydrol-earth-syst-sci-discuss.net/hess-2016-304/hess-2016-304-AC3supplement.pdf

Interactive comment on Hydrol. Earth Syst. Sci. Discuss., doi:10.5194/hess-2016-304, 2016. 